\title{
Tandem Mass Spectrometry Studies of Acetone and Acetone/Water Cluster Ions
}

\author{
V. Aviyente, * M. Iraqi, T. Peres, and C. Lifshitz** \\ Department of Physical Chemistry and The Fritz Haber Research Center for Molecular Dynamics, The \\ Hebrew University of Jerusalem, Jerusalem, Israel
}

\begin{abstract}
Ion clusters were formed in a temperature-variable high-pressure ion source from neat acetone and acetone/water mixtures and subjected to tandem mass spectrometry studies-unimolecular and collisionally activated mass-analyzed ion kinetic energy spectroscopy. The predominance of water loss from $\mathrm{H}^{+}\left(\mathrm{H}_{2} \mathrm{O}\right)(\mathrm{A})_{I=3}$, where $\mathrm{A} \equiv$ acetone, suggests that the solvation sphere around $\mathrm{H}_{3} \mathrm{O}^{+}$does not close at $l=3$, contrary to the case of acetonitrile or dimethyl ether. The results may be interpreted in terms of suggested ion structures which involve isomerization enroute to dissociation. The virtual absence of $\mathrm{H} / \mathrm{D}$ scrambling in the collisionally activated dissociation of $\mathrm{H}_{3} \mathrm{O}^{+}(\mathrm{DA})_{3}, \mathrm{DA} \equiv$ acetone- $d_{6}$, and of $\mathrm{D}_{3} \mathrm{O}^{+}(\mathrm{A})_{3}$ means that if enolization takes place, it is a rate-determining step in an irreversible isomerization. The stability of $\mathrm{H}^{+}\left(\mathrm{H}_{2} \mathrm{O}\right)(\mathrm{A})_{3}$ is a dominant factor in the observation of acetone loss from $\mathrm{H}^{+}\left(\mathrm{H}_{2} \mathrm{O}\right)(\mathrm{A})_{4}$. (J Am Soc Mass Spectrom 1991, 2, 113-119)
\end{abstract}

A cetone has been detected in the upper troposphere and lower stratosphere $[1,2]$. Mixed acetone/water proton bound clusters $\mathrm{H}^{+}\left(\mathrm{CH}_{3} \mathrm{COCH}_{3}\right)_{1}\left(\mathrm{H}_{2} \mathrm{O}\right)_{n}$ occur naturally in the atmosphere as so-called nonproton hydrates (NPH). They are also monitored, in quantitative determinations of acetone volume mixing ratios, by aircraft-borne chemical ionization mass spectrometry $[3,4]$. The structure, kinetics, and dynamics of these mixed proton bound clusters have therefore applicative significance.

The influence of solvation on chemical reactions is also of interest from the point of view of bridging the gap between the gas phase and solution phase chemistry. There has been considerable interest recently in the solvation shells of the proton surrounded by water and acetonitrile [5-7], methanol [7-9], and ethanol [7]. The ionic hydrogen bond and ion solvation have been studied through thermochemical measurements [10]. Preferential solvation of hydrogen ions in mixed water/amine ion clusters has been monitored through competitive decomposition processes via metastable peak intensities [11]. Multiphoton ionization in combination with a time-of-flight reflectron has been demonstrated [12-14] to be a powerful technique for studying the influence of solvation on intracluster ion-molecule reactions and unimolecular decomposition of acetone cluster ions [12], protonated

\footnotetext{
* Permanent address: Chemistry Department Bogaziçi Üniversitesi Bebek, Istanbul, Turkey.

** Archie and Marjorie Sherman Professor of Chemistry.

Address reprint requests to $C$. Lifshitz, Department of Physical Chemistry and The Fritz Haber Research Center for Molecular Dynamics, The Hebrew University of Jerusalem, Jerusalem 91904, Israel.
}

acetaldehyde clusters [13], and mixed ammonia/ acetone cluster ions [14].

It has been demonstrated that stability in hydrogen-bonded species is achieved by the symmetric positioning of molecules around a central proton or protonated molecule [15-17]. This is true, for example, for mixed proton bound clusters $\mathrm{H}^{+}(\mathrm{A})_{l}\left(\mathrm{H}_{2} \mathrm{O}\right)_{n}$ r where $l=3$ and $n=1$. In the structure assigned to them $[5,16,18,19]$ (structure 1), $\mathrm{H}_{3} \mathrm{O}^{+}$forms the core ion and the molecules $A$ are symmetrically attached to the three hydrogen atoms sharing the positive charge. This structure has been calculated [20] by $a b$ initio methods for $A \equiv$ acetonitrile and has been found to be the most stable tetramer.

We have recently employed [8] a high-pressure temperature-variable ion source to produce proton bound clusters, which were subjected to tandem mass spectrometry (MS/MS) studies, unimolecular and collisionally activated mass-analyzed ion kinetic energy spectrometry (MIKES). Our interest in mixed acetone/water proton bound clusters was aroused by their very different behavior when compared with acetonitrile/water clusters. Under collisional activation (CA), $\mathrm{H}^{+}\left(\mathrm{CH}_{3} \mathrm{CN}\right)_{3}\left(\mathrm{H}_{2} \mathrm{O}\right)$ does not lose water at all $[5,21]$, whereas $\mathrm{H}^{+}\left(\mathrm{CH}_{3} \mathrm{COCH}_{3}\right)_{3}\left(\mathrm{H}_{2} \mathrm{O}\right)$ demonstrates water loss to be the base peak in the spectrum [21]. The fact that the acetonitrile cluster ion does not lose water has been noticed earlier [19] for low-energy CA spectra. This has been ascribed to ion structure 1 in which the acetonitrile molecules are in the periphery of the ion and the water molecule is shielded by them. The behavior of dimethyl ether in $\mathrm{H}^{+}\left(\left(\mathrm{CH}_{3}\right)_{2} \mathrm{O}\right)_{3} \mathrm{H}_{2} \mathrm{O}$ is similar to that of acetonitrile and $a$ similar structure is justified $[6,22]$. Stace and 


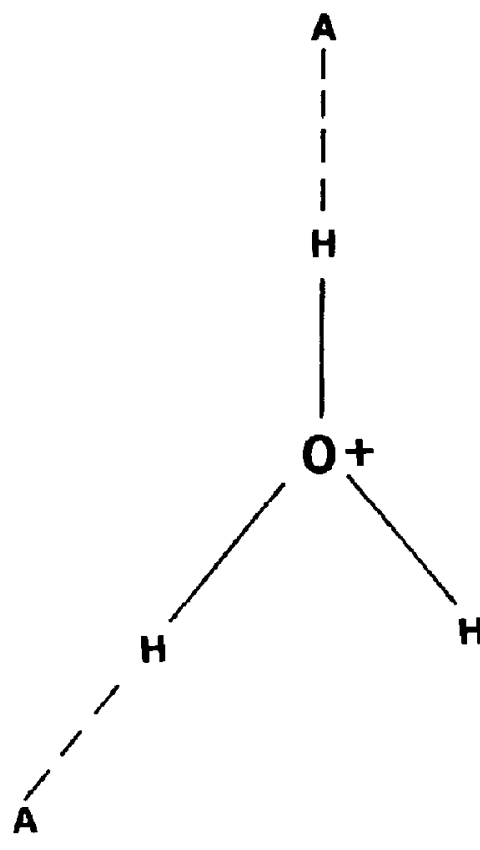

1

Moore [18] have already observed that the behavior of acetone is different. They observed for unimolecular fragmentations of metastable ions $\mathrm{H}^{+}\left(\mathrm{CH}_{3} \mathrm{COCH}_{3}\right)_{1}\left(\mathrm{H}_{2} \mathrm{O}\right)_{n}$ that water is eliminated whenever $n=1-2$ and acetone is lost for $n \neq l-2$. If this behavior persists not only for unimolecular fragmentations but also for $C A$, structure 1 may not be appropriate for acetone, since water has to be in the periphery of the ion in order to be lost under CA. In the present study we have subjected proton bound acetone and acetone/water clusters to MS/MS investigations in order to better understand the structure and dynamics of these clusters.

\section{Experimental}

Measurements were performed on a VG ZAB-2F double-focusing mass spectrometer of reversed geometry (VG Analytical Ltd., Wythenshawe, Manchester, UK) [23]. For MIKES, the magnetic field was set to select the ions of desired $m / z$ value under investigation; ionic products of their decompositions in the second field-free region, between the magnetic and electrostatic analyzers, were detected by scanning the electric-sector potential under conditions of good energy resolution with the energy resolving $\beta$-slit partially closed. Collisional activation spectra [24] were obtained by using $\mathrm{He}$ as the collision gas on $6-8 \mathrm{keV}$ ions. The desired operating conditions have been described in the literature for metastable ion and $\mathrm{CA}$ spectra $[25,26]$.

Ions were formed by electron impact in a tempera-
Table 1. MIKE and $\mathrm{CA}$ spectra for $\mathrm{H}^{+}\left(\mathrm{CH}_{3} \mathrm{COCH}_{3}\right)$

\begin{tabular}{lrrrrrrrrrrr}
\hline \hline$m / z$ & 15 & 26 & 27 & 28 & 29 & 30 & 31 & 36 & 37 & 38 & 39 \\
MIKE & - & - & - & - & - & - & 100 & 13 & - & - & 8 \\
CA & 5 & 4 & 6 & 2 & 11 & 1 & 40 & 3 & 4 & 9 & 27 \\
\hline \hline$m / z$ & 41 & 42 & 43 & 44 & 53 & 55 & 57 & 58 & & & \\
MIKE & 89 & - & 26 & 27 & - & - & - & 26 & & & \\
CA & 28 & 22 & 72 & 18 & 4 & 5 & 10 & 100 & & &
\end{tabular}

ture- and pressure-variable drift ion source [27]. The operating conditions adequate for obtaining cluster ions have been described previously $[8,28]$. Temperatures were between $200 \mathrm{~K}$ and $273 \mathrm{~K}$ and the pressure range was $0.01-0.1$ torr.

Acetone- $d_{6}$ was from Aldrich, 99.5 atom \% D.

\section{Results and Discussion}

The following clusters were observed in pure acetone: $\mathrm{H}^{+}(\mathrm{A})_{m}, \mathrm{CH}_{3}^{+}(\mathrm{A})_{m}, \quad \mathrm{C}_{2} \mathrm{H}_{3} \mathrm{O}^{+}(\mathrm{A})_{m}$, where $\mathrm{A} \equiv$ acetone, in agreement with previous data from ion-molecule reactions [29-31] and ionization of neutral clusters [12, 32]. In addition, we observed in mixtures of water and acetone the NPH ions, $\mathrm{H}^{+}\left(\mathrm{CH}_{3} \mathrm{COCH}_{3}\right)_{1}\left(\mathrm{H}_{2} \mathrm{O}\right)_{n}$, as well as a few mixed nonprotonated clusters, $\left(\mathrm{CH}_{3} \mathrm{COCH}_{3}\right)_{l}\left(\mathrm{H}_{2} \mathrm{O}\right)_{n}^{+}$.

\section{Neat Proton Bound Acetone Cluster lons $\mathrm{H}^{+}(A)_{m}$}

Tables 1 and 2 summarize the data for MIKES and collisionally activated dissociation (CAD) on the neat clusters. Ions observed under MIKES and CAD of the protonated monomer (Table 1) have been observed as fragment ions in the troposphere and lower stratosphere. This is particularly true for $m / z$ values 29,31 , and 43 [33]. As noticed before for methanol [8], the protonated monomer undergoes considerable fragmentation, while the higher clusters undergo mainly desolvation-evaporation of a single solvent molecule -each. Similar reactions were reported before [32] for cluster ions formed by ionization of neutral clusters. The present mass spectra demonstrated weak signals at $m / z 99$ and 157 corresponding to $\mathrm{C}_{6} \mathrm{H}_{11} \mathrm{O}^{+}$and (A) $\cdot \mathrm{C}_{6} \mathrm{H}_{11} \mathrm{O}^{+}$, but the MIKE spectra did not demonstrate the elimination of water from $\mathrm{H}^{+}(\mathrm{A})_{m}$ ions with

Table 2. MIKE and CA spectra of $\mathrm{H}^{+}\left(\mathrm{CH}_{3} \mathrm{COCH}_{3}\right)_{m}, m=2-4$

\begin{tabular}{|c|c|c|c|c|c|c|c|}
\hline \multirow{2}{*}{$\begin{array}{l}\text { Ion } \\
(\mathrm{A}=\text { Acetone })\end{array}$} & \multirow[b]{2}{*}{$m / z$} & \multicolumn{3}{|c|}{$\begin{array}{c}\text { MIKE } \\
\text { value of } m\end{array}$} & \multicolumn{3}{|c|}{$\begin{array}{c}\text { CA } \\
\text { value of } m\end{array}$} \\
\hline & & 2 & 3 & 4 & 2 & 3 & 4 \\
\hline $\mathrm{CH}_{3} \mathrm{CO}^{+}$ & 4.3 & & & & 2 & & \\
\hline $\mathrm{CH}_{3} \mathrm{COCH}_{3}^{+}$ & 58 & & & & 10 & & \\
\hline $\mathrm{H}^{+}(\mathrm{A})$ & 59 & 100 & & & 100 & 3 & \\
\hline $\mathrm{H}^{+}\left(\mathrm{CH}_{3} \mathrm{CO}(\mathrm{A})\right.$ & 102 & & & & 2 & & \\
\hline$H^{+}(A)_{2}$ & 117 & & 100 & & & 100 & 11 \\
\hline$H^{+}(A)_{3}$ & 175 & & & 100 & & & 100 \\
\hline
\end{tabular}


Table 3. MIKE spectra of mixed acetone $(=A)$ and water $(=W)$ cluster ions

\begin{tabular}{|c|c|c|c|c|c|c|c|c|}
\hline Ion & $m / z$ & $\mathrm{H}^{+}(\mathrm{A})(\mathrm{W})$ & $\mathrm{H}^{+}(\mathrm{A})_{2}(\mathrm{~W})$ & $\mathrm{H}^{+}(\mathrm{A})_{2}(\mathrm{~W})_{2}$ & $\mathrm{H}^{+}(\mathrm{A})_{3}(\mathrm{~W})$ & $\mathrm{H}^{+}(\mathrm{A})_{3}(\mathrm{~W})_{2}$ & $\mathrm{H}^{+}(\mathrm{A})_{4}(\mathrm{~W})$ & $\mathrm{H}^{+}(\mathrm{A})_{4}(\mathrm{~W})_{2}$ \\
\hline$\overline{\mathrm{H}+(\mathbf{A})}$ & 59 & 100 & 0.5 & & $\overline{0.5}$ & & & \\
\hline $\mathrm{H}^{+}(\mathrm{A})(\mathrm{W})$ & 77 & & 1.0 & & 0.03 & & & \\
\hline$\left.H^{+} \mid A\right)_{2}$ & 117 & & 100 & 86 & 1.2 & 0.3 & & 0.16 \\
\hline $\mathrm{H}^{+}(\mathrm{A})_{2}(\mathrm{~W})$ & 135 & & & 100 & $\mathbf{a}$ & & & 0.1 \\
\hline $\mathrm{H}^{+}(\mathrm{A})_{2}(\mathrm{~W})_{2}$ & 153 & & & & & 0.4 & & 0.1 \\
\hline $\mathrm{H}^{+}(\mathrm{A})_{3}$ & 175 & & & & 100 & & 2 & 0.3 \\
\hline $\mathrm{H}^{+}(\mathrm{A})_{3}(\mathrm{~W})$ & 193 & & & & & 100 & 100 & 1.7 \\
\hline $\mathrm{H}^{+}(\mathrm{A})_{3}(\mathrm{~W})_{2}$ & 211 & & & & & & & 26 \\
\hline$H^{+}(A)_{4}$ & 233 & & & & & & 1 & \\
\hline $\mathrm{H}^{+}(\mathrm{A})_{4}(\mathrm{~W})$ & 251 & & & & & & & 100 \\
\hline
\end{tabular}

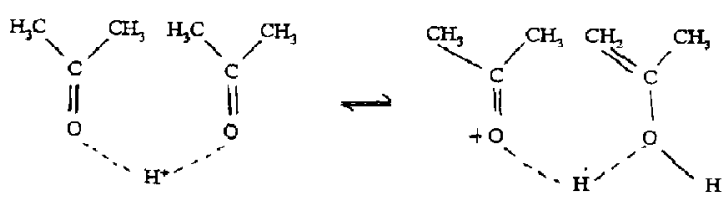

Scheme I

$m \geq 2$, reported previously by Castleman and coworkers [12], but not seen by Stace and Shukla [32]. Castleman observed [12] that the presence of water molecules in a cluster suppresses the dehydration reaction. The dehydration reaction,

$$
\mathrm{H}^{+}(\mathrm{A})_{m} \rightarrow(\mathrm{A})_{m-2} \cdot \mathrm{C}_{6} \mathrm{H}_{11} \mathrm{O}^{+}+\mathrm{H}_{2} \mathrm{O}
$$

cannot be inhibited in the freld-free region of our instrument in which the pressure is $\leq 3.8 \times 10^{-8}$ torr and where water is not present. The present result, for cluster ions made by ion-molecule reactions, is in agreement with that for cluster ions made by ionization of neutral clusters [32], namely, desolvation

$$
\mathrm{H}^{+}(\mathrm{A})_{m} \rightarrow \mathrm{H}^{+}(\mathrm{A})_{m-1}+\mathrm{A}
$$

is the only reaction observed in the metastable time range of several microseconds. The mechanism for dehydration has been suggested to involve the keto/enol equilibrium [12] (Scheme I), although alternative mechanisms are conceivable as well (Scheme II).

In Scheme I, contrary to Scheme II, the dehydration product $\mathrm{C}_{6} \mathrm{H}_{11} \mathrm{O}^{+}$is protonated mesityl oxide [12], which is the product of acid-catalyzed dehydration in solution. The mechanism suggested by Scheme I has an advantage over Scheme II, since it explains

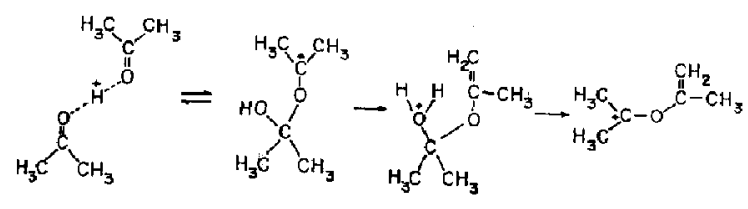

Scheme II the fact that the dehydration reaction is depressed in the presence of water [12].

\section{Mixed Acetone / Water Clusters}

MIKE and CAD spectra for mixed acetone/water clusters are represented in Tables 3 and 4, respectively. Water elimination is the predominant reaction in all but one of the mixed proton bound acetone/water cluster ions (NPH ions) that we have studied,

$$
\mathrm{H}^{+}(\mathrm{A})_{l}(\mathrm{~W})_{n} \rightarrow \mathrm{H}^{+}(\mathrm{A})_{1}(\mathrm{~W})_{n-1}+\mathrm{H}_{2} \mathrm{O}
$$

whereas acetone loss,

$$
\mathrm{H}^{+}(\mathrm{A})_{l}(\mathrm{~W})_{n} \rightarrow \mathrm{H}^{+}(\mathrm{A})_{l-1}(\mathrm{~W})_{n}+\mathrm{CH}_{3} \mathrm{COCH}_{3}
$$

is a minor channel or not observed at all. This is also true for $\mathrm{H}^{+}(A)_{3}(\mathrm{~W})$ as has been ohserved earlier [18, 21]. The only ion for which this trend is reversed is $\mathrm{H}^{+}(\mathrm{A})_{4}(\mathrm{~W})$. In $\mathrm{H}^{+}(\mathrm{A})_{4}(\mathrm{~W})_{2}$ water elimination is again the major channel, but acetone loss is still quite abundant. The present results partially contradict previous data [18] that have observed acetone loss to be the dominant reaction channel whenever $n \neq l-2$. CAD enhances consecutive water losses relative to unimolecular MIKES.

Preferential solvation of hydrogen ions in mixed clusters has been studied previously $[11,14,18]$. It has been suggested [18] that the specific effects in the acetone/water system are solcly due to the larger dipole moment of acetone compared to that of water. It is questionable whether this in itself is sufficient to explain the experimental observations and whether structural isomerization en route to dissociation need not be invoked. The solvation sphere around $\mathrm{H}_{3} \mathrm{O}^{+}$ does not close at $l=3$, contrary to the case of acetonitrile or dimethyl ether. But four acetone molecules, i.e., $l=4$, do shield the water molecule in $\mathrm{H}^{+}(\mathrm{A})_{4}(\mathrm{~W})$ and prevent, to a large extent, its elimination under either MIKES or CAD. A factor which may have to be considered when comparing $\mathrm{H}^{+}\left(\mathrm{CH}_{3} \mathrm{CN}\right)_{3} \mathrm{~W}$ with $\mathrm{H}^{+}(\mathrm{A})_{3} \mathrm{~W}$ ( $\mathrm{A} \equiv$ acetone) is the steric hindrance of the acetone methyl groups. $\mathrm{Ab}$ initio calculations are required to determine the most stable structure for each cluster ion. It is quite plausi- 
Table 4. CAD spectra of mixed acetone $(=\mathrm{A})$ and water $(=\mathrm{W})$ cluster ions

\begin{tabular}{|c|c|c|c|c|c|c|c|c|c|c|c|c|c|}
\hline Ion & $m / z$ & $\mathrm{H}^{+}(\mathrm{A})(\mathrm{W})$ & $\mathrm{H}^{+}(\mathrm{A})(\mathrm{W})_{2}$ & $\mathrm{H}^{+}(\mathrm{A})(\mathrm{W})_{3}$ & $(\mathrm{~A})_{2}(\mathrm{~W})^{+}$ & $\mathrm{H}^{+}(\mathrm{A})_{2}(\mathrm{~W})$ & $\mathrm{H}^{+}(\mathrm{A})_{2}(\mathrm{~W})_{2}$ & $(\mathrm{~A})_{3}(\mathrm{~W})^{+}$ & $\mathrm{H}^{+}(\mathrm{A})_{3}(\mathrm{~W})$ & $\mathrm{H}^{+}(\mathrm{A})_{3}(\mathrm{~W})_{2}$ & $\mathrm{H}^{+}(\mathrm{A})_{3}(\mathrm{~W})_{3}$ & $\mathrm{H}^{+}(\mathrm{A})_{4}(\mathrm{~W})$ & $\mathrm{H}^{+}(\mathrm{A})_{4}(\mathrm{~W})_{2}$ \\
\hline & 31 & 2 & & & & & & & & & & & \\
\hline & 39 & 2 & & & & & & & & & & & \\
\hline & 43 & 3 & 4 & & & & & & & & & & \\
\hline & 47 & 3 & 15 & & & & & & & & & & \\
\hline & 57 & & & 10 & & & & & & & & & \\
\hline $\mathrm{A}^{+}$ & 58 & 6 & 5 & 1 & & & & & & & & & \\
\hline $\mathrm{H}^{+}(\mathrm{A})$ & 59 & 100 & 15 & 4 & & 5 & & & 1.5 & 2 & & & \\
\hline $\mathrm{H}^{+}(\mathrm{A})(\mathrm{W})$ & 77 & & 100 & 18 & & 8 & & & 1.5 & 0.7 & & 2 & \\
\hline & 79 & & & 5 & & & & & & & & & \\
\hline $\mathrm{H}^{+}(\mathrm{A})(\mathrm{W})_{2}$ & 95 & & & 100 & & & 34 & & & 0.4 & & & \\
\hline (A) ${ }_{2}^{+}$ & 116 & & & & 100 & & & & & & & & \\
\hline $\mathrm{H}^{+}(\mathrm{A})_{2}$ & 117 & & & & & 100 & 69 & & 22 & 17 & 29 & 5 & 3 \\
\hline (A) $)_{2}\left(W^{2}\right)^{-}$ & 134 & & & & & & & 100 & & & & & \\
\hline $\mathrm{H}^{+}(\mathrm{A})_{2}(\mathrm{~W})$ & 135 & & & & & & 100 & & 15 & 8 & 87 & 11 & 1.5 \\
\hline $\mathrm{H}^{+}(\mathrm{A})_{2}(\mathrm{~W})_{2}$ & 153 & & & & & & & & & 9 & 41 & & 1 \\
\hline $\mathrm{H}^{+}(\mathrm{A})_{2}(\mathrm{~W})_{3}$ & 171 & & & & & & & & & & 33 & & \\
\hline$(\mathrm{A})_{3}^{+}$ & 174 & & & & & & & 67 & & & & & \\
\hline $\mathrm{H}^{+}(\mathrm{A})_{3}$ & 175 & & & & & & & & 100 & 6 & 13 & 4 & 3 \\
\hline $\mathrm{H}^{+}(\mathrm{A})_{3}(\mathrm{~W})$ & 193 & & & & & & & & & 100 & 29 & 100 & 28 \\
\hline $\mathrm{H}^{+}(\mathrm{A})_{3}(\mathrm{~W})_{2}$ & 211 & & & & & & & & & & 100 & & 35 \\
\hline $\mathrm{H}^{+}(\mathrm{A})_{4}$ & 233 & & & & & & & & & & & $\mathbf{9}$ & \\
\hline $\mathrm{H}^{+}(\mathrm{A})_{4}(\mathrm{~W})$ & 251 & & & & & & & & & & & & 100 \\
\hline
\end{tabular}


<smiles></smiles>

ble that the most stable structure for $\mathrm{H}^{+}(\mathrm{A})_{3} \mathrm{~W}$ is 2a but that isomerization precedes water elimination. It should be pointed out that water elimination occurs from $\mathrm{H}^{+}(\mathrm{A})_{3} \mathrm{~W}$ unimolecularly, while acetone loss is enhanced considerably under collisional activation. Unimolecular metastable reactions normally prefer low-energy routes involving rearrangements, while collisionally activated dissociations promote higherenergy simple bond cleavages. Water elimination from structure 2a withoul prior rearrangement should be accompanied by a reverse activation energy and a pronounced kinetic energy release. This is not the case and water elimination is, in fact, accompanied by a lower kinetic energy release $(\langle T\rangle=19 \mathrm{meV})$ than acetone loss $(\langle T\rangle=23 \mathrm{meV})$.

There are several alternative possibilities for the isomeric structure of $\mathbf{2 a}$ (Figure 1 ). The simplest alternative (2a') involves the protonated acetone trimer loosely bound to a water molecule. The protonated acetone trimer itself has been calculated [34] to have the planar stable dimer structure with an additional acetone molecule moving quite freely in the periphery. Another alternative is keto/enol isomerization $[12,29,35]$ (Scheme I), which has been suggested for the acetone clusters. It is quite plausible that the most stable structure for $\mathrm{H}^{+}(\mathrm{A})_{3} \mathrm{~W}$ is the keto form, 2a, but that isomerization to the enol form, $2 \mathbf{b}$, precedes water elimination. We have tested this assumption by deuterium labeling experiments (see next section). Isomer $2 b$ (like $2 a^{\prime}$ ) is able to lose water from the periphery without any reverse activation energy. A third alternative way of explaining the dominance of water loss in mixed acetone/water clusters is to consider linear polymer or cyclic polymer structures involving covalent bonds, such as $2 c$ or $2 d$, for $\mathrm{H}^{+} \mathrm{A}_{3} \mathrm{~W}$. However, while structures such as $3 a$, which involve enolization of acetone, can explain the predominance of acetone loss from $\mathrm{H}^{+} \mathrm{A}_{4} \mathrm{~W}$, this is not the case for the "polymeric" structures $3 b$ or $3 c$. These structures do not offer a unique behavior for $\mathrm{H}^{+} \mathrm{A}_{4} \mathrm{~W}$, namely,<smiles></smiles><smiles></smiles><smiles>[CH2]C(C)([13CH3])OC([13CH3])([13CH3])O</smiles><smiles>CC1(C)OI(O)OC(C)(C)OC(C)(C)O1</smiles> 
<smiles>C=C(C)[O+]([CH]OC=C(C)C)COC(C)=O</smiles>

$3 a$

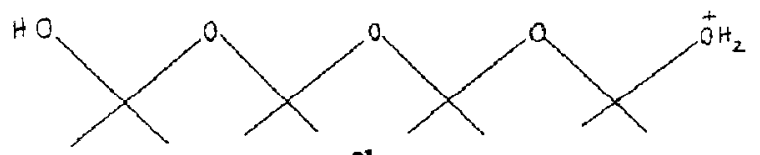

3b

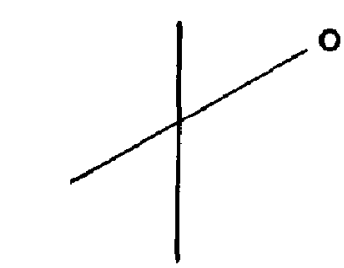

4

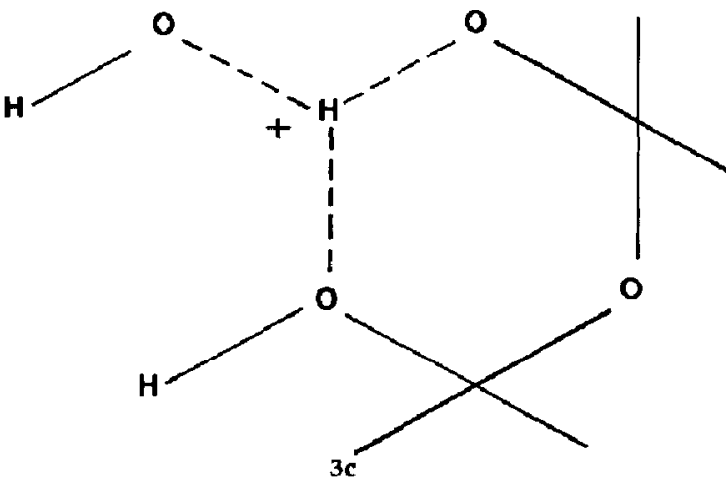

acetone loss. It is not known, at this point, whether the keto/enol $(\mathbf{2 a} / \mathbf{2 b})$ isomerization barrier or the cluster ion/polymer ion $(\mathbf{2 a} / \mathbf{2 c})$ isomerization barrier is lower than the simple bond cleavage for acetone loss from $2 \mathrm{a}$. This would be required for water loss to be competitive according to the potential energy profile of Figure 1.

\section{Mixed $\mathrm{CD}_{3} \mathrm{COCD}_{3} / \mathrm{H}_{2} \mathrm{O}$ and $\mathrm{CH}_{3} \mathrm{COCH}_{3} / \mathrm{D}_{2} \mathrm{O}$ Clusters}

Enolization of acetone in its clusters can find support through isotopic labeling [35]. MTKF and CAD spectra of cluster ions formed in $\mathrm{CD}_{3} \mathrm{COCD}_{3} / \mathrm{H}_{2} \mathrm{O}$ and

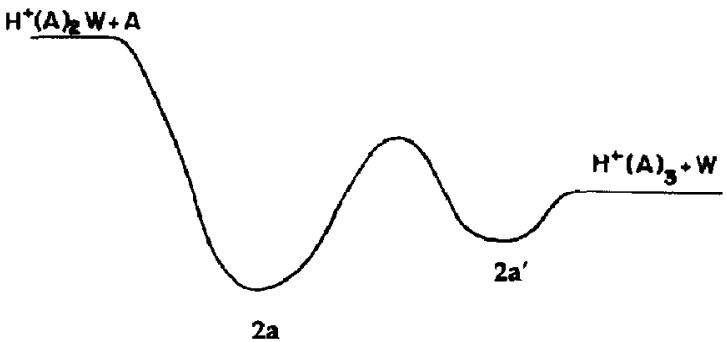

Figure 1. Schematic potential energy profile for the unimolecular fragmentation of $\mathrm{H}^{+}(\mathrm{A})_{3} \mathrm{~W}$ ( $\mathrm{A} \equiv$ acetone, $W=$ water); 2a and $2 \mathrm{a}^{\prime}$ are two isomeric structures for $\mathrm{H}^{+}(\mathrm{A})_{3} \mathrm{~W}$ (see text). Alternative isomeric structures instead of 2a' could possibly be $2 b$ or $2 c$.

$\mathrm{CH}_{3} \mathrm{COCH}_{3} / \mathrm{D}_{2} \mathrm{O}$ mixtures demonstrated elimination of $19 \mathrm{u}(\mathrm{HDO})$. The results for deuterated isotopomer ions of 2 are summarized in Table 5. While cluster inns containing $\mathrm{X}_{3} \mathrm{O}^{+}$groups with $X=\mathrm{H}$ as well as $\mathrm{D}$ eliminate $\mathrm{HDO}$, the acetone eliminated from $\mathrm{CD}_{3} \mathrm{COCD}_{3}$ containing ions was pure $\mathrm{CD}_{3} \mathrm{COCD}_{3}$ and that containing $\mathrm{CH}_{3} \mathrm{COCH}_{3}$ was pure $\mathrm{CH}_{3} \mathrm{COCH}_{3}$. These results favor the ketone structures $2 \mathrm{a}$ and $2 \mathrm{a}^{\prime}$ in which the hydrogens in $\mathrm{H}_{3} \mathrm{O}^{+}$ become partially equilibrated but where there is no isotopic scrambling in the acetones eliminated. It should be pointed out, however, that the mass spectra of $\mathrm{D}_{2} \mathrm{O} / \mathrm{A}$ mixtures demonstrated abundant ions at $m / z=197$ and 198, indicating production of $\mathrm{X}_{3} \mathrm{O}^{+}(\mathrm{A})_{3}$ ions in which the acetones were partially scrambled with mono- or dideuterated species in the ion source or in the mixture introduced into the ion source. This holds also for other clusters in the mixture.

Since $\mathrm{HDO}$ elimination is a very minor process from either $\mathrm{H}_{3} \mathrm{O}^{+}(\mathrm{DA})_{3}$ or $\mathrm{D}_{3} \mathrm{O}^{+}(\mathrm{A})_{3}$, it is not plausible that once $2 b$ is formed en route to water elimination it isomerizes back to 2a. If enolization takes place, it has to be a rate-determining isomerization en route to dissociation.

\section{Conclusions}

Isomerization of mixed acetone/water cluster ions is suggested to play a role in water eliminations and in determining the preferential solvation of hydrogen ions in mixed acetone/water clusters. Three acetone molecules do not screen one water molecule in the mixed proton bound cluster, contrary to the behavior

Table 5. CAD spectra of selected deuterated mixed clusters

\begin{tabular}{lcccc}
\hline \multirow{2}{*}{$\begin{array}{c}\text { Neutral } \\
\text { loss }\end{array}$} & \multicolumn{4}{c}{ Reactant ion (DA $\left.\equiv \mathrm{CD}_{3} \mathrm{COCD}_{3}\right)$} \\
\cline { 2 - 5 } $\mathrm{H}_{2} \mathrm{O}$ & $\mathrm{H}^{+}(\mathrm{DA})_{3}$ & $\mathrm{D}_{3} \mathrm{O}^{+}(\mathrm{A})_{3}$ & $\mathrm{DH}_{2} \mathrm{O}^{+}(\mathrm{DA})_{3}$ & $\mathrm{HD}_{2} \mathrm{O}^{+}(\mathrm{A})_{3}$ \\
$\mathrm{HDO}$ & 2 & 100 & 100 & 70 \\
$\mathrm{H}_{2} \mathrm{O}$ & 100 & 4 & 90 & 100 \\
\hline
\end{tabular}


of acetonitrile or dimethyl ether, whereas the fourth does. What seems to be the dominant factor under MIKES is the stability of the reaction products. This dictates the loss of acetone from $\mathrm{H}^{+}(\mathrm{A})_{4}(\mathrm{~W})$, while water losses are observed for the other mixed clusters.

\section{Acknowledgments}

This research was supported by grant no. 89-00028 from the United States-Israel Binational Science Foundation (BSF), Jerusalem, Israel. Professor A. W. Castleman, Jr., serves as the American cooperative investigator for this grant. We thank Dr. M. Meot-Ner (Mautner) and Professor A. W. Castleman, Jr., for valuable discussions, and the referees for valuable suggestions.

\section{References}

1. Hauck, G.; Arnold, F. Nature 1984, 311, 547.

2. Arnold, F.; Hauck, G. Nature 1985, 315, 307.

3. Arnold, F.; Knop, G.; Ziereis, H. Nature 1986, 321, 505.

4. Arnold, F.; Knop, G. Int. I. Mass Spectrom. Ion Processes 1987, 81, 33

5. Iraqi, M.; Lifshitz, C. Int. J. Mass Spectrom. Ion Processes 1986, 71, 245.

6. Graul, S. $\mathrm{T}_{-}$S Squires, R. R. Int. J. Mass Spectrom. Ion Processes 1989, 94, 41.

7. Mestdagh, J. M.; Binet, A.; Sublemontier, O. J. Phys. Chem. $1989,93,8300$.

8. Iraqi, M.; Lifshitz, C. Int. J. Mass Spectrom. Ion Processes $1989,88,45$.

9. Gratul, S. G.; Squires, R, R. Int. J. Mass Spectrom. Ion Processes 1987, 81, 183.

10. Meot-Ner (Mautner), M. J. Am. Chem. Soc. 1984, 106, 1265.

11. Stace, A. J. J. Am. Chem. Soc. 1984, 106, 2306.

12. Treng, W. B.; Wei, S.; Castleman, A. W. Jr. I. Am. Chem. Soc. 1989, 111, 6035.

13. Tzeng, W. B.; Wei, S.; Castleman, A. W. Jr. Chem. Phys. Lett. 1990, 168, 30.
14. Tzeng, W. B.; Wei, S.; Castleman, A. W. Jr. Chem. Phys. Lett. $1990,166,343$.

15. Grimsrud, E. P.; Kebarle, P. J. An. Chem. Soc. 1973, 95, 7939.

16. Hiraoka, K.; Grimsrud, E. P.; Kebarle, P. J. Am. Chem. Soc. 1974, 96, 3359.

17. Lau, Y. K.; Saluja, P. P. S.; Kebarle, P. J, Am. Chem. Soc. 1980, 102, 7429.

18. Stace, A. J.; Moore, C. I. Phys. Chem. 1982, 86, 3681.

19. Böhringer, H.; Amold, F. Nalure 1981, $290,321$.

20. Deakyne, C. A.; Meot-Ner (Mautner), M.; Campbell, C. L.; Hughes, M. G.; Murphy, S. P. I. Chem. Phys. 1986, 84, 4958.

21. Lifshitz, C.; Iraqi, M. In The Structure of Small Molecules and Ions; Naaman, R., and Vager, Z., Eds.; Plenum: New York, 1988.

22. Iraq $\$$., Lifshitz, C. Unpublished results.

23. Morgan, R. P.; Beynon, J. H.; Bateman, R. H.; Green, B. M. Int. J. Mass Spectrom. Ion Phys. 1978, 28, 171.

24. McLafferty, F. W. Interpretation of Mass Spectra; Benjamin: New York, 1973.

25. Terlouw, J. K.; Burgers, P. C.; Hommes, H. Org. Mass Spectrom. 1979, 14, 387.

26. Burgers, P. C.; Holmes, J. L.; Szulejko, J. E.; Mommers, A. A.; Terlouw, I. K. Org. Mass Spectrom. 1983, 18, 254.

27. van Koppen, P. A. M.; Kemper, P. R.; Illies, A. J.; Bowers, M. T. Int. J. Mass Spectrom. Ion Processes 1983, 54, 263.

28. Lifshitz, C.; Louage, F. J. Phys. Chem. 1989, 93, 5633.

29. Munson, M. S. B. J. Am. Chem. Soc. 1965; 87.5313.

30. MacNeil, K. A. G.; Futrell, J. H. J. Phys. Chem. 1972, 76, 409.

31. Luczynski, Z.; Wincel, H. Int. J. Mass Spectrom. Ion Phys$1977,23,37$.

32. Stace, A. J.; Shukla, A. K. J. Phys. Chem. 1982, 86, 865.

33. Knop, G.; Diplomarbeit, MPI für Kernphysik, Heidelberg, 1986.

34. Yamabe, S.; Minato, T.; Hirao, K. Can. J. Chem. 1983, 61, 2827.

35. Meot-Ner, M., personal communication, January 1990. 